\title{
Blood Rheology Adjustments in Rats after a Program of Intermittent Exposure to Hypobaric Hypoxia
}

\author{
Santiago Esteva, Pere Panisello, Joan Ramon Torrella, Teresa Pagés, and Ginés Viscor
}

\begin{abstract}
Esteva, Santiago, Pere Panisello, Joan Ramon Torrella, Teresa Pagés, and Ginés Viscor. Blood rheology adjustments in rats after a program of intermittent exposure to hypobaric hypoxia. High Alt. Med. Biol. 10:275-281, 2009.-Intermittent hypobaric hypoxia ( $\mathrm{IHH}$ ) exposure induces a rise in hemoglobin concentration and an increase in erythrocyte mass in both rats and humans. Although this response increases blood oxygen transport capacity, paradoxically, it could impair blood flow and gas exchange because of the blood viscosity alterations associated with the rising hematocrit. In the present study, male rats were subjected to an IHH program consisting of a daily 4-h session for 5 days/week until they had completed 22 days of hypoxia exposure in a hypobaric chamber at a simulated altitude of $5000 \mathrm{~m}$. Blood samples were taken at the end of the exposure period $(\mathrm{H})$ and at 20 (P20) and 40 (P40) days after the end of the program and were compared to control (C) maintained at sea- level pressure. Apparent blood viscosity $\left(\eta_{\mathrm{a}}\right)$ and plasma viscosity $\left(\eta_{\mathrm{p}}\right)$ were measured in a cone-plate microviscometer. Although the hematocrit significantly increased in the $\mathrm{H}$ group, blood apparent viscosity did not differ among groups, ranging from 7.67 to $6.57 \mathrm{mPa} \bullet \mathrm{sec}$ at a shear rate of $90 \mathrm{sec}^{-1}$. Relative blood viscosity showed a clear increase (about $27 \%$ ) in $\mathrm{H}$ rats, mainly due to the significant decrease in plasma viscosity. This finding could be interpreted as a compensatory response, which reduced the effect of increased erythrocyte mass volume on wholeblood viscosity. Oxygen delivery index and blood oxygen potential transport capacity remained unchanged in all groups. These data indicate that the IHH program has a deep but transitory effect on red cell parameters and a moderate effect on blood rheological behavior.
\end{abstract}

Key Words: intermittent hypoxia; hypobaric chamber; blood rheological behavior; blood viscosity; red blood cells

\section{Introduction}

TNERMITTENT OR CONTINUOUS HYPOXIA has gained popu1 larity as a tool for the enhancement of aerobic capacity, and an increasing number of elite athletes use these strategies in combination with training programs (Levine and StrayGundersen, 1997; Wilber, 2004; Robach et al., 2006). The most serious effects of high altitude on human physiology are due to the low oxygen partial pressure of the inspired air; consequently, several adjustments are needed to improve the tissue oxygen availability (Leon-Velarde et al., 2000). Hypobaric hypoxia increases ventilation (West, 1993), arteriovenous $\mathrm{O}_{2}$ difference, hemoglobin concentration, and hematocrit (Ferretti et al., 1990a; Rodriguez et al., 1999). It also has profound effects on the structure and function of skeletal muscle tissue (Ferretti et al., 1990b; Hoppeler et al., 1990; Panisello et al., 2008), it induces acid-base alterations and affects the affinity of hemoglobin for oxygen (Cerretelli and Samaja, 2003), and it raises erythropoietin levels (Eckardt et al., 1989).

Moreover, prolonged exposure to hypobaric hypoxia also induces physical deterioration, which increases with altitude (Kayser, 1994). This deleterious effect is reflected in a marked decrease in body weight, due in part to a reduction in muscle mass (Terrados, 1992). Also, due to the increase in red cell mass, the viscosity of blood (apparent viscosity) can be increased with the possibility of a subsequent reduction in oxygen transport capacity. Other circulatory complications such as deep venous thrombosis may be caused by abnormally higher hematocrit, although compensatory mechanisms can reduce the effective hematocrit after intense exercise (Reinhart et al., 1983). Prolonged exposure to high altitude in nonnative residents or relatively recent high altitude populations frequently yields a complex syndrome: Monge's disease or chronic mountain sickness (Leon-Velarde et al., 2005;

Departament de Fisiologia, Facultat de Biologia, Universitat de Barcelona, Barcelona, Spain. 
Rivera-Chira et al., 2007; Xing et al., 2008). To prevent the negative effects of chronic hypoxia exposure, several procedures alternating short hypoxia exposure with immediate recovery in normoxia have been proposed (Brugniaux et al., 2006; Robach et al., 2006). These intermittent hypoxiaexposure procedures are performed in hypoxic chambers and have led to relevant findings, such as the efficacy of a hypoxic stimulus to elicit an erythropoietic response and also other nonerythropoietic physiological adjustments affecting aerobic capacity. Thus, these exposure protocols have been considered as efficient methods for high altitude acclimatization (Wagner et al., 1987; Sutton et al., 1988; Richalet et al., 1992).

In the present study we analyze some of the parameters of the adaptive responses previously described in humans that are elicited by intermittent hypoxia. We applied an IHH exposure protocol to laboratory rats to study its effect on blood rheology and other rheological parameters during hypoxia exposure and recovery periods. Preliminary results from this study were presented at the Annual Main Meeting of the Society for Experimental Biology (Glasgow, April 2007).

\section{Materials and Methods}

\section{Animals}

A total of 70 male Sprague-Dawley rats, aged 6 weeks and with average body weight of $312.8 \pm 4.6 \mathrm{~g}$ at the beginning of the experiment, were randomly divided into four groups. The first experimental group of 18 rats $(\mathrm{H}$, for hypoxic) was submitted to a program of IHH (described in detail later), and blood was drawn at the end of this program. A second experimental group of 13 rats (P20, for posthypoxia 20 days) was simultaneously submitted to the same program, but blood samples were obtained 20 days after the end of the protocol. A third experimental group of 14 rats (P40, for posthypoxia 40 days) was also simultaneously submitted to the same exposure program, but samples were obtained 40 days after the end of the protocol. Finally, 22 rats were used as a triple control group (group C, for control). Control animals were maintained under the same conditions as the three experimental groups. Samples from 9 control animals (subgroup C1) were obtained at the same time as those from $\mathrm{H}$; samples from another 9 controls (subgroup C2) were obtained at the same time as those from P20, and, finally, samples from the remaining 4 (subgroup C3) were taken at the same time as those from P40. No significant differences in body weight among control and experimental animals were detected in this study. Animal growth was normal, and the body mass of the last set of animals was $428.6 \pm 9.4 \mathrm{~g}$.

This study was part of a general procedure for studying peripheral gas exchange; thus all rats were killed and used to obtain other tissues samples.

The present study was authorized by the University of Barcelona's Ethical Committee for Animal Experimentation and ratified, in accordance with current Spanish legislation, by the Departament de Medi Ambient i Habitatge (file 1899) of the Catalan Government (Generalitat de Catalunya).

\section{Hypobaric chamber}

A hypobaric chamber was used to submit the rats to the IHH program. The total volume of the hypobaric chamber was approximately $450 \mathrm{~L}$, which allowed the housing of three rat cages. The chamber walls were made of polymethyl methacrylate plastic, which facilitated observation of animal behavior during the protocol. Relative vacuum was developed by a rotational vacuum pump (TRIVAC D5E, Leybold, Köln, Germany) by regulating the airflow rate at the inlet with a micrometric valve. Inner pressure was controlled by two differential pressure sensors (ID 2000, Leybold, Köln, Germany) connected to a vacuum controller (Combivac IT23, Leybold, Köln, Germany) driving a diaphragm pressure regulator (MR16, Leybold, Köln, Germany). Depending on the simulated altitude required, a low-pressure set point was established in a control system. After the desired level was reached, the internal barometric pressure of the chamber was regulated and maintained by the control system.

\section{IHH program}

After a quarantine of 2 weeks, animals were moved into the conditioned room containing the hypobaric chamber. An initial period of 5 days, free of disturbance, was allowed for complete habituation. The IHH program consisted of 4-h sessions 5 days a week for 4 weeks and 2 additional days, thus making 22 days of exposure to hypoxia ( $88 \mathrm{~h}$ in total). The simulated altitude reached during each session was $5000 \mathrm{~m}$ $(400 \mathrm{mmHg}=533 \mathrm{hPa})$. Group $\mathrm{C}$ was subjected to the same procedure, although the hypobaric chamber was open to room pressure. Animals had access to laboratory chow and tap water ad libitum. However, for technical reasons, water reservoirs were removed during hypoxia sessions from all animal groups.

\section{Blood sampling procedure}

Blood samples were collected by cardiac puncture. Prior to collection, animals were anesthetized with urethane $(1.5 \mathrm{~g} / \mathrm{kg}$ $\mathrm{BM}$ ). Sodium heparin was used as an anticoagulant. A fraction of each blood sample was separated for immediate hematological analyses, which were always completed within $10 \mathrm{~min}$ of blood withdrawal. A second portion of the sample was simultaneously processed for blood rheology determinations. The cellular portion of a third part of the blood sample was removed by centrifugation, and the plasma obtained was separated without delay for the measurement of viscosity. Hematological and hemorheological values were determined immediately after collection.

\section{Hematology and blood rheology}

The following hematological parameters were measured using an electronic cell counter (Celltac $\alpha$, Nihon Kohden Corp., Tokyo, Japan): red blood cells (RBC), hemoglobin $(\mathrm{Hb})$, hematocrit $(\mathrm{Hc})$, mean corpuscular volume (MCV), mean corpuscular hemoglobin $(\mathrm{MCH})$, and mean corpuscular hemoglobin concentration (MCHC). Total plasma protein and fibrinogen concentrations were determined by spectrophotometric techniques according to Bradford (1976) and sulfite precipitation (Rampling and Gaffney, 1976) methods, respectively. The apparent viscosity $\left(\eta_{\mathrm{a}}\right)$ of blood and plasma was measured using a cone-plate microviscosimeter (Brookfield Digital Rheometer Model DV-III + , Middleboro, MA, USA) equipped with a CP40 spindle $\left(0.8^{\circ}\right)$ and connected to a thermostatic bath. Brookfield viscosity standard fluid 5 $\left(4.9 \mathrm{mPa} / \mathrm{sec}\right.$ at $\left.25^{\circ} \mathrm{C}\right)$ was used for calibration just before each measuring session. A sample volume of $0.5 \mathrm{~mL}$ was tested at different shear rates $(\dot{\gamma})$, ranging from 2.25 to 
$450 \mathrm{sec}^{-1}$. Measurements were done at $38.0^{\circ} \mathrm{C}$. Due to the low viscosity values and to obtain the highest accuracy, plasma viscosity was measured only at $450 \mathrm{sec}^{-1}$, since the Newtonian behavior of plasma is well established.

Considering limitations due to the viscoelastic behavior of the whole blood and for easy understanding, the effect of plasma viscosity on whole-blood apparent viscosity was considered by studying the quotient of the apparent viscosities of whole blood and plasma, also known as blood relative viscosity $\left(\eta_{\mathrm{r}}\right)$. According to Chien and colleagues (1970), erythrocyte aggregability $\left(\mathrm{RBC}_{\mathrm{a}}\right)$ and deformability $\left(\mathrm{RBC}_{\mathrm{d}}\right)$ are the main factors affecting blood viscosity at low and high shear rates, respectively. As a consequence, the contribution of these microrheological characteristics to blood flow properties could be estimated from the variation of apparent blood viscosity values within low (when cell plasma protein interactions are strong) and high (with high probabilities of cellcell interaction) ranges of shear rate, respectively. Thus, we applied the following formulas, also defined as the degree of shear dependence (Usami et al., 1969):

$$
\begin{aligned}
\mathrm{RBC}_{\mathrm{a}} & =\left(\eta_{2.25}-\eta_{4.5}\right) / \eta_{4.5} \\
\mathrm{RBC}_{\mathrm{d}} & =\left(\eta_{225}-\eta_{450}\right) / \eta_{450}
\end{aligned}
$$

where $\eta_{x}$ indicates the apparent blood viscosity at a shear rate level $\dot{\gamma}=x$.

Calculations were also performed to evaluate the effect of blood viscosity changes induced by hypobaric hypoxia on oxygen transport function. We calculated two different coefficients previously defined in the literatur: first, the oxygen delivery index $(\mathrm{Hc} / \eta)$ (Koch, 1995), which shows the relationship between the hematocrit (Hc) and blood viscosity $(\eta)$ and, second, the blood oxygen potential transport capacity $(\beta[\mathrm{Hb}] / \eta)$ (Hedrick et al., 1986), which relates the hemoglobin oxygen capacity $(\beta)$ and hemoglobin concentration $[\mathrm{Hb}]$ with blood viscosity $(\eta) . \beta$ values were assumed to be $1.34 \mathrm{~mL}$ $\mathrm{O}_{2} \bullet \mathrm{g}^{-1}$ at $38^{\circ} \mathrm{C}$ for the four experimental groups. For the oxygen delivery index and oxygen potential transport ca- pacity calculations, blood viscosity value at a shear rate of $90 \mathrm{sec}^{-1}$ was taken.

\section{Statistics}

Data for all parameters are expressed as the sample mean \pm standard error of the mean. Differences between the experimental and control groups were analyzed by a one-way ANOVA test. Afterward, a multiple comparison test using the Scheffé procedure was run to determine the differences between each pair of experimental and control conditions. Descriptive statistics and analyses of normality were made with the SigmaStat software package, whereas one-way ANOVA and the Scheffé test were performed by the application of suitable subroutines from the SPPS/PC + package (SPSS, Inc., Chicago, IL, USA). Differences were considered statistically significant for $p<0.05$.

\section{Results}

Normal growth was not affected by $\mathrm{IHH}$, as reflected by body weight changes during the protocol. Moreover, no statistically significant differences were found among C1, C2, and C3 for any of the parameters and, unless otherwise indicated, these three control groups were combined for all figures and tables and named group $\mathrm{C}$.

\section{Hematological parameters}

Hematological parameters for the three species are given in Table 1. The one-way ANOVA and Scheffé tests showed significant differences among the four experimental groups in most of the hematological parameters. Hematological changes after exposure to hypobaric hypoxia were characterized by a significant increase in erythrocytes in the hypoxic group ( $\mathrm{H}$ vs. $\mathrm{C}, \mathrm{P} 20$, and $\mathrm{P} 40 ; p<0.001$ ), hematocrit ( $\mathrm{H}$ vs. $\mathrm{C}, \mathrm{P} 20$, and $\mathrm{P} 40 ; p<0.001$ ), and hemoglobin concentration (H vs. $\mathrm{C}$, $\mathrm{P} 20$, and $\mathrm{P} 40 ; p<0.001)$. Also, some significant differences in the hematological indexes MCV and $\mathrm{MCH}$ were found; they

Table 1. Hematological Parameters, Plasma Viscosity, Microrheological Indexes, Blood Oxygen Potential

\begin{tabular}{|c|c|c|c|c|c|}
\hline & & $C(n=17)$ & $H(n=10)$ & P20 $(n=13)$ & $\mathrm{P} 40(\mathrm{n}=14)$ \\
\hline RBC (cells $\bullet 10^{3} \cdot \mu \mathrm{L}^{-1}$ ) & $\mathrm{a}$ & $8.81 \pm 0.10$ & $9.98 \pm 0.20^{\mathrm{a}}$ & $8.91 \pm 0.16$ & $8.60 \pm 0.14$ \\
\hline $\mathrm{Hb}\left(\mathrm{g} \cdot \mathrm{dL}^{-1}\right.$ & $\mathrm{a}$ & $15.66 \pm 0.19$ & $18.75 \pm 0.37^{\mathrm{a}}$ & $16.26 \pm 0.28$ & $15.56 \pm 0.25$ \\
\hline Hc $(\%)$ & $\mathrm{a}$ & $47.03 \pm 0.66$ & $55.22 \pm 1.02^{\mathrm{a}}$ & $48.09 \pm 0.79$ & $47.03 \pm 0.77$ \\
\hline $\operatorname{MCV}\left(\mu \mathrm{m}^{3}\right)$ & $\mathrm{b}$ & $53.33 \pm 0.41$ & $55.25 \pm 0.37^{c}$ & $53.86 \pm 0.50$ & $54.72 \pm 0.44$ \\
\hline $\mathrm{MCH}(\mathrm{pg})$ & $\mathrm{C}$ & $17.77 \pm 0.12$ & $18.76 \pm 0.15^{\mathrm{b}}$ & $18.03 \pm 0.85$ & $17.92 \pm 0.20$ \\
\hline $\mathrm{MCHC}(\%)$ & & $33.34 \pm 0.17$ & $33.96 \pm 0.16$ & $33.90 \pm 0.21$ & $33.09 \pm 0.23$ \\
\hline WBC (cells $\bullet 10^{3} \cdot \mu \mathrm{L}^{-1}$ ) & $\mathrm{d}$ & $9.85 \pm 0.83$ & $13.50 \pm 1.47^{c}$ & $12.61 \pm 0.65$ & $9.40 \pm 0.78$ \\
\hline Plasma viscosity $(\mathrm{mPa} \bullet \mathrm{sec})$ & $\mathrm{a}$ & $1.24 \pm 0.02$ & $1.14 \pm 0.02^{\mathrm{b}}$ & $1.25 \pm 0.03$ & $1.30 \pm 0.03$ \\
\hline Total plasma proteins $\left(\mathrm{g} \bullet 100 \mathrm{~mL}^{-1}\right)$ & $\mathrm{e}$ & $4.95 \pm 0.08$ & $4.69 \pm 0.18$ & $4.88 \pm 0.08$ & $5.34 \pm 0.08^{b}$ \\
\hline Fibrinogen $\left(\mathrm{mg} \bullet 100 \mathrm{~mL}^{-1}\right)$ & & $129.26 \pm 8.42$ & $96.01 \pm 7.67$ & $128.52 \pm 9.76$ & $136.64 \pm 9.89$ \\
\hline $\mathrm{RBC}_{\mathrm{a}}$ & $\mathrm{f}$ & $0.46 \pm 0.03^{b}$ & $0.66 \pm 0.03$ & $0.61 \pm 0.03$ & $0.66 \pm 0.03$ \\
\hline $\mathrm{RBC}_{\mathrm{d}}$ & & $0.13 \pm 0.02$ & $0.14 \pm 0.07$ & $0.16 \pm 0.03$ & $0.11 \pm 0.01$ \\
\hline $\mathrm{Hc} / \eta(\mathrm{mPa} \bullet \mathrm{sec})^{-1}$ & & $7.34 \pm 0.35$ & $7.50 \pm 0.37$ & $7.25 \pm 0.67$ & $7.14 \pm 0.23$ \\
\hline$\beta[\mathrm{Hb}] / \eta\left(\mathrm{mLO}_{2} \bullet 100 \mathrm{~mL}^{-1} \bullet \mathrm{mPa}^{-1} \bullet \mathrm{sec}^{-1}\right)$ & & $3.30 \pm 0.15$ & $3.39 \pm 0.37$ & $3.26 \pm 0.30$ & $3.18 \pm 0.10$ \\
\hline
\end{tabular}
Transport Capacity, and Oxygen Delivery Index for the Different Groups of Experimental Animals

Mean values and standard error are indicated. Significant differences between groups are indicated by the following code: (a) $\mathrm{H}$ vs. all other groups, (b) $\mathrm{C}$ vs. $\mathrm{H}$, (c) H vs. C and P40, (d) H vs. P40, (e) P40 vs. all other groups, and (f) C vs. all other groups. Levels of significance are indicated as ${ }^{\mathrm{a}} p<0.001,{ }^{\mathrm{b}} p<0.01$, or ${ }^{\mathrm{c}} p<0.05$. 


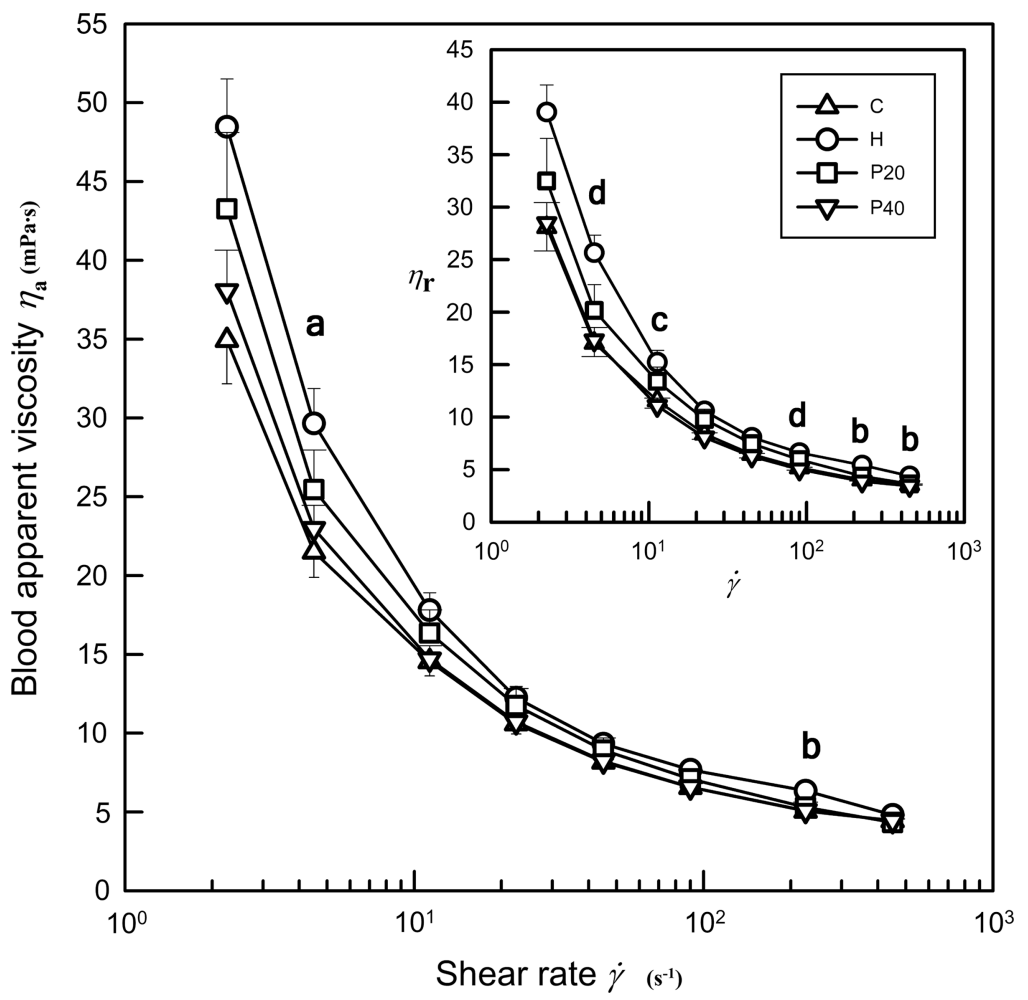

FIG. 1. Rheograms of apparent blood viscosity $\left(\eta_{\mathrm{a}}\right)$ and relative viscosity $\left(\eta_{\mathrm{r}}\right)$ for whole blood from the different experimental groups. Vertical bars represent standard error of the mean. Significant differences are indicated according to the following code: (a) $p<0.05 \mathrm{H}$ vs. C; (b) $p<0.01 \mathrm{H}$ vs. all other groups; (c) $p<0.05 \mathrm{H}$ vs. P40; (d) $p<0.05 \mathrm{H}$ vs. C and P40.

were slightly increased in the $\mathrm{H}$ group and later returned to basal values.

\section{Blood rheology parameters}

As expected, blood samples showed a non-Newtonian shear-thinning behavior manifested as a clear reduction of viscosity as the applied shear rate increased in each experimental condition. When the apparent viscosity of the native whole blood was compared by means of a one-way ANOVA, a significant effect of the shear rate on blood viscosity was found (Fig. 1).

Plasma viscosity values (Table 1 ) showed a significant decrease in the $\mathrm{H}$ group compared with the other three groups ( $\mathrm{H}$ vs. $\mathrm{C}, \mathrm{P} 20$, and $\mathrm{P} 40 ; \mathrm{p}<0.01$ ). Fibrinogen and plasma protein concentration showed a similar variation profile.

Table 1 also shows that, whereas RBC deformability indexes were very uniform, ranging from 0.11 to 0.16 , the RBC aggregability indexes (Table 1 ) differed widely between $C$ and the other experimental groups (C vs. H, P20, and P40; $p<0.05)$. However, these results must be considered with caution, because these indexes indicate the rheological behavior and red cell interactions in cone-plate conditions, which are distinct from those in vivo in microcirculatory vessels.

Blood oxygen potential transport capacity and the oxygen delivery indexes are listed in Table 1 . In both indexes, the four experimental groups were similar, although group $\mathrm{H}$ showed a trend to be higher, thus indicating that oxygen supply to the tissues could be slightly improved in the hypoxia group.

The relationship between apparent and relative blood viscosities and the hematocrit is plotted in Fig. 2. A clear-cut trend was observed in animals according to their group. Both graphs show that group $\mathrm{H}$ is clearly apart from the others because of its high viscosity and hematocrit values.

\section{Discussion}

Many studies have reported that chronic hypoxia induces deleterious effects on body mass (Boyer and Blume, 1984; Rose et al., 1988). A recent experimental study of chronic IHH in rats with a 4 by 4 and 2 by 2 alternating daily schedule of sea level and simulated 4600-m altitude demonstrated a severe body weight reduction and compromised survival rate (Siques et al., 2006). However, possibly due to the lower degree of hypoxia exposure, we detected no negative effects on normal growth rate. This indicates that our hypoxia exposure regime offers good compatibility with the standard living conditions of these experimental animals.

\section{Hematological parameters}

The hematological parameters and oxygen transport indexes for the four experimental groups were within the range of the results previously found in rats (Siques et al., 2006) and humans (Casas et al., 2000a; Casas et al., 2000b). The most remarkable adaptations to the acclimatizing program are probably those observed in the hematological profile. The significant increases in red blood cells, hematocrit, and hemoglobin concentration values in group $\mathrm{H}$ are clearly associated with an enhancement of blood oxygen transport capacity. After the exposure period was over, raised values of $\mathrm{RBC}, \mathrm{Hb}$, and $\mathrm{Hc}$ had the tendency to return to the lower normal range. Consequently, it seems clear that intermittent exposure to hypoxia can also stimulate erythropoiesis in the 

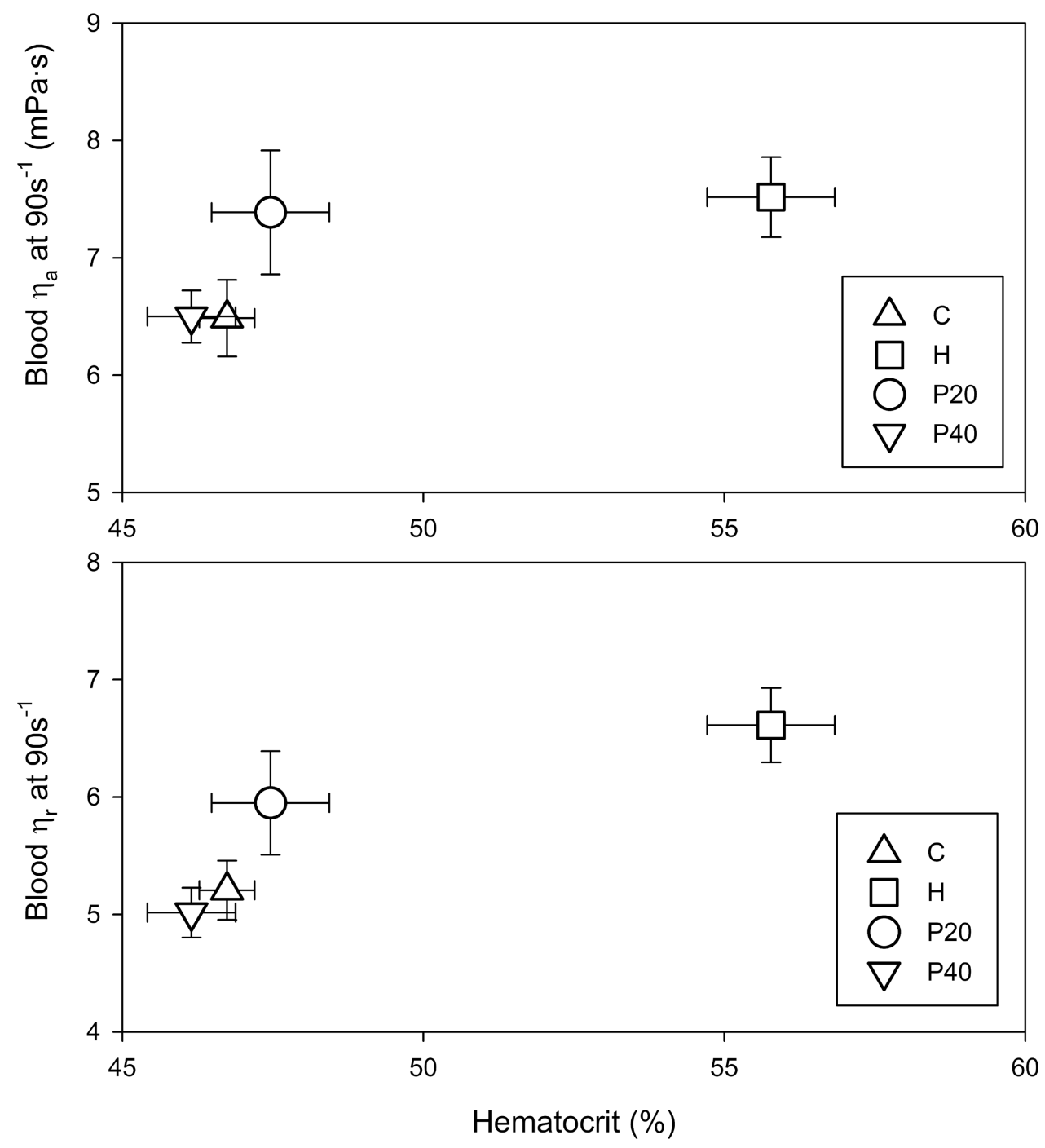

FIG. 2. Relationships between apparent blood viscosity (upper panel) and relative viscosity (lower panel) and mean hematocrit for each experimental group.

rat to the same extent as chronic exposure (Lamanna et al., 1992; Rivera et al., 1994; Biljanovic-Paunovic et al., 1996). Slight differences in hematimetric indexes may be due to the influence of a significantly higher percentage of reticulocytes in group $\mathrm{H}$ rats, thus causing a small increase in the volume of blood cells (Rodriguez et al., 1999; Savourey et al., 2004).

\section{Blood rheology parameters}

At low shear rates, the whole-blood viscosity values for all groups of rats were notably higher than those described in humans, even in previous studies in our laboratory (Rodriguez et al., 1999). As a consequence of the rise in the red cell packed volume induced by the intermittent hypoxia exposure program, one would expect a greater increase in blood viscosity; but the hemorheological characteristics did not significantly change in our observations after the exposure period, although a clear increasing trend was observed in the hypoxic group compared to the others, especially at low shear rates. Regrettably, for technical reasons, viscometer precision at very low rotational speeds is substantially reduced when low-viscosity biological fluids are measured. For this reason, data at low shear rates must be considered with caution. In spite of this uncertainty, a coherent trend toward increased values for whole-blood viscosity induced by hypoxia was observed (Fig. 1). The effect is more apparent at low shear rates than at higher ones, thus indicating different dynamics between erythrocyte deformability, the main factor influencing blood viscosity at high shear rates, and erythrocyte aggregability, the most important factor affecting blood viscosity at low shear rates. As reflected by the high viscosity values at low shear rate, our data indicate that, besides deformability, aggregation of rat erythrocytes may be an important factor limiting blood oxygen supply to the tissues.

The presence of some compensatory mechanisms could eventually prevent the negative effects evoked by an excessive increase in blood viscosity. The decrease in plasma viscosity and possible erythrocyte microrheological changes may be the main factors driving these compensatory responses. Plasma protein concentration showed a similar figure to plasma viscosity changes in this study and, of interest, fibrinogen concentration tightly followed these variations, maintaining in each case about $25 \%$ of total plasma protein mass. A similar response that regulates blood viscosity has been 
described in transgenic mice overexpressing erythropoietin (Vogel et al., 2003). Changes in blood rheological behavior during hypoxia exposure can markedly affect microcirculation in peripheral tissues, resulting in more severe frostbite damage than in normoxic conditions (Zengren et al., 1999).

The oxygen carrying capacity and oxygen delivery indexes were similar in the four experimental groups (no significant differences were found), in spite of marked differences in hematocrit, blood viscosity, and hemoglobin concentration. Several factors, other than the well-known adjustment between hematocrit and blood viscosity for sustained oxygen delivery to tissues (optimal hematocrit theory), may explain this finding. Our data seem to indicate that the blood oxygencarrying capacity and oxygen- delivery index are only slightly affected by increased hematocrit induced by hypoxia in rats of the $\mathrm{H}$ group. A similar finding was obtained in a previous comparative study in different species of vertebrates (Viscor et al., 2003).

The relationship between apparent and relative blood viscosities and hematocrit shows that a different time course for viscosity changes could exist when the four groups are compared (Fig. 2). This graph shows asymmetry in the effect on whole-blood viscosity between erythropoiesis activation and the recovery to normal conditions. Thus, 40 days after the end of exposure the rats had almost recovered from the effects of our IHH program. This time course does not differ from that described in humans (Rodriguez et al., 2000) and must be considered when planning exposure for preacclimatization expeditions or competition events.

We conclude that intermittent exposure to hypobaric hypoxia (simulated altitude) activates the erythropoietic response, but this does not necessarily imply a direct improvement in the aerobic performance capacity of rats. In fact, the oxygen delivery index and blood oxygen potential transport capacity remained unchanged in all groups due to a compensatory response that reduced the effect of increased red cell mass volume on whole-blood viscosity. All these data indicate that the IHH program applied has a deep but transitory effect on red cell parameters and a very moderate effect on blood rheological behavior.

\section{Acknowledgments}

This study was supported by grant BFI2003-03439 through the Spanish Plan Nacional I + D + I. The authors thank Rafael Pedret for his technical assistance and Robin Rycroft (Language Advisory Service-UB) for editing the manuscript.

\section{Disclosures}

Authors Esteva, Panisllo, Torrella, Pagés, and Viscor have no conflicts of interest or financial ties to disclose.

\section{References}

Biljanovic-Paunovic L., Clemons G.K., Ivanovic Z., and Pavlovic-Kentera V. (1996). Erythropoietin \& erythroid progenitors in rats exposed to chronic hypoxia. Indian J. Med. Res. 104:304-310.

Boyer S.J., and Blume F.D. (1984). Weight loss and changes in body composition at high altitude. J. Appl. Physiol. 57:1580-1585.

Bradford M.M. (1976). A rapid and sensitive method for the quantitation of microgram quantities of protein utilizing the principle of protein-dye binding. Anal. Biochem. 72:248-254.
Brugniaux J.V., Schmitt L., Robach P., Jeanvoine H., Zimmermann, H., Nicolet G., Duvallet A., Fouillot J.P., and Richalet J.P. (2006). Living high-training low: tolerance and acclimatization in elite endurance athletes. Eur. J. Appl. Physiol. 96:6677.

Casas M., Casas H., Pages T., Rama R., Ricart A., Ventura J.L., Ibañez J., Rodriguez F.A., and Viscor G. (2000a). Intermittent hypobaric hypoxia induces altitude acclimation and improves the lactate threshold. Aviat. Space Environ. Med. 71:125-130.

Casas H., Casas M., Ricart A., Rama R., Ibañez J., Palacios L., Rodriguez F.A., Ventura J.L., Viscor G., and Pages T. (2000b). Effectiveness of three short intermittent hypobaric hypoxia protocols: hematological responses. JEPonline 3:38-45.

Cerretelli P., and Samaja M. (2003). Acid-base balance at exercise in normoxia and in chronic hypoxia: revisiting the "lactate paradox." Eur. J. Appl. Physiol. 90:431-448.

Chien S., Usami S., Dellenback R.J., and Gregersen M.I. (1970). Shear-dependent deformation of erythrocytes in rheology of human blood. Am. J. Physiol. 219:136-142.

Eckardt K.U., Boutellier U., Kurtz A., Schopen M., Koller E.A., and Bauer C. (1989). Rate of erythropoietin formation in humans in response to acute hypobaric hypoxia. J. Appl. Physiol. 66:1785-1788.

Ferretti G., Boutellier U., Pendergast D.R., Moia C., Minetti A.E., Howald H., and Di Prampero P.E. (1990a). Oxygen transport system before and after exposure to chronic hypoxia. Int. J. Sports Med. 11(Suppl. 1):S15-S20.

Ferretti G., Hauser H., and Di Prampero, P.E. (1990b). Maximal muscular power before and after exposure to chronic hypoxia. Int. J. Sports Med. 11(Suppl. 1):S31-S34.

Hedrick M.S., Duffield D.A., and Cornell L.H. (1986). Blood viscosity and optimal hematocrit in a deep-diving mammal, the northern elephant seal (Mirounga Angustirostris). Can. J. Zool. 64:2081-2085.

Hoppeler H., Kleiner E., Schlegel C., Claassen H., Howald H., Kayar S.R., and Cerretelli P. (1990). Morphological adaptations of human skeletal muscle to chronic hypoxia. Int. J. Sports Med. 11(Suppl. 1):S3-S9.

Kayser B. (1994). Factors limiting exercise performance in man at high altitude.

Koch H.J. (1995). Possible role of erythrocyte sedimentation rate, hematocrit and oxygen supply of tissue in clinical investigations. Cardiology. 86:177-178.

Lamanna J.C., Vendel L.M., and Farrell R.M. (1992). Brain adaptation to chronic hypobaric hypoxia in rats. J. Appl. Physiol. 72:2238-2243.

Leon-Velarde F., Gamboa A., Chuquiza J.A., Esteba W.A., Rivera-Chira M., and Monge C.C. (2000). Hematological parameters in high altitude residents living at 4,355, 4,660, and 5,500 meters above sea level. High Alt. Med. Biol. 1:97-104.

Leon-Velarde F., Maggiorini M., Reeves J.T., Aldashev A., Asmus I., Bernardi L., Ge R.L., Hackett P., Kobayashi T., Moore L.G., Penaloza D., Richalet J.P., Roach R., Wu T., Vargas E., Zubieta-Castillo G., and Zubieta-Calleja, G. (2005). Consensus statement on chronic and subacute high altitude diseases. High Alt. Med. Biol. 6:147-157.

Levine B.D., and Stray-Gundersen J. (1997). "Living high-training low:" effect of moderate-altitude acclimatization with lowaltitude training on performance. J. Appl. Physiol. 83:102-112.

Panisello P., Torrella J.R., Esteva S., Pages T., and Viscor G. (2008). Capillary supply, fibre types and fibre morphometry in rat tibialis anterior and diaphragm muscles after intermittent exposure to hypobaric hypoxia. Eur. J. Appl. Physiol. 103:203-213.

Rampling M.W., and Gaffney P.J. (1976) The sulphite precipitation method for fibrinogen measurements: its use on small 
samples in the presence of fibrinogen degradation products. Clin. Chim. Acta. 67:43-52.

Reinhart W.H. Stäubli M., and Straub P.W. (1983). Impaired red cell filterability with elimination of old RBC during a $100 \mathrm{~km}$ race. J. Appl. Physiol. 54:827-830.

Richalet J.P., Bittel J., Herry J.P., Savourey G., Le Trong J.L., Auvert J.F., and Janin, C. (1992). Use of a hypobaric chamber for pre-acclimatization before climbing Mount Everest. Int. J. Sports Med. 13:S216-S220.

Rivera M., Leon-Velarde F., Huicho L., and Monge C. (1994). Bone marrow oxygen consumption and erythropoiesis in chronically hypoxic rats. Life Sci. 55:1027-1032.

Rivera-Chira M., Leon-Velarde F., and Huicho L. (2007). Treatment of chronic mountain sickness: critical reappraisal of an old problem. Respir. Physiol. Neurobiol. 158:251-265.

Robach P., Schmitt L., Brugniaux J.V., Nicolet G., Duvallet A., Fouillot J.P., Moutereau S., Lasne F., Pialoux V., Olsen N.V., and Richalet J.P. (2006). Living high-training low: effect on erythropoiesis and maximal aerobic performance in elite Nordic skiers. Eur. J. Appl. Physiol. 97:695-705.

Rodriguez F.A., Casas H., Casas M., Pages T., Rama R., Ricart A., Ventura J.L., Ibañez J., and Viscor, G. (1999). Intermittent hypobaric hypoxia stimulates erythropoiesis and improves aerobic capacity. Med. Sci. Sports Exerc. 31:264-268.

Rodriguez F.A., Ventura J.L., Casas M., Casas H., Pages T., Rama R., Ricart A., Palacios L., and Viscor G. (2000). Erythropoietin acute reaction and haematological adaptations to short, intermittent hypobaric hypoxia. Eur. J. Appl. Physiol. 82:170-177.

Rose M.S., Houston C.S., Fulco C.S., Coates G., Sutton J.R., and Cymerman, A. (1988). Operation Everest. II: nutrition and body composition. J. Appl. Physiol. 65:2545-2551.

Savourey G., Launay J.C., Besnard Y., Guinet A., Bourrilhon C., Cabane D., Martin S., Caravel J.P., Pequignot J.M., and CottetEmard, J.M. (2004). Control of erythropoiesis after high altitude acclimatization. Eur. J. Appl. Physiol. 93:47-56.

Siques P., Brito J., Leon-Velarde F., Barrios L., Cruz J.J., Lopez V., and Herruzo R. (2006). Time course of cardiovascular and hematological responses in rats exposed to chronic intermittent hypobaric hypoxia $(4600 \mathrm{~m})$. High Alt. Med. Biol. 7:72-80.

Sutton J.R., Reeves J.T., Wagner P.D., Groves B.M., Cymerman A., Malconian M.K., Rock P.B., Young P.M., Walter S.D., and Houston C.S. (1988). Operation Everest II: oxygen transport during exercise at extreme simulated altitude. J. Appl. Physiol. 64:1309-1321.
Terrados N. (1992). Altitude training and muscular metabolism. Int. J. Sports Med. 13:S206-S209.

Usami S., Chien S., and Gregersen M.I. (1969). Viscometric characteristics of blood of the elephant, man, dog, sheep and goat. Am. J. Physiol. 217:884-890.

Viscor G., Torrella J.R., Fouces V., and Pages T. (2003). Hemorheology and oxygen transport in vertebrates: a role in thermoregulation? J. Physiol. Biochem. 59:277-286.

Vogel J., Kiessling I., Heinicke K., Stallmach T., Ossent P., Vogel O., Aulmann M., Frietsch T., Schmid-Schonbein H., Kuschinsky W., and Gassman M. (2003). Transgenic mice overexpressing erythropoietin adapt to excessive erythrocytosis by regulating blood viscosity. Blood. 102:2278-2284.

Wagner P.D., Sutton J.R., Reeves J.T., Cymerman A., Groves B.M., and Malconian M.K. (1987). Operation Everest II: pulmonary gas exchange during a simulated ascent of Mt. Everest. J. Appl. Physiol. 63:2348-2359.

West J.B. (1993). Acclimatization and tolerance to extreme altitude. J. Wilderness Med. 4:17-26.

Wilber R.L. (2004). Altitude Training and Athletic Performance. Human Kinetics, Champaign, IL

Xing G., Qualls C., Huicho L., Rivera-Chira M., Stobdan T., Slessarev M., Prisman E., Ito S., Wu H., Norboo A., Gamboa J.L., Claydon V.E., Fisher J., Zenebe G., Gebremedhin A., Hainsworth R., Verma A., and Appenzeller O. (2008). Adaptation and mal-adaptation to ambient hypoxia: Andean, Ethiopian and Himalayan patterns. PLoS ONE 3:e2342.

Zengren Y., Jiaying L., Fengzhi L., Peihua Y., Youmei L., and Fangren S. (1999). Effect of acute hypoxia and hypoxic acclimation on hemorheological behavior in rats with frostbite. Clin. Hemorheol. Microcirc. 20:189-195.

Address correspondence to: Ginés Viscor, Ph.D. Departament de Fisiologia, Facultat de Biologia Universitat de Barcelona Av. Diagonal, 645; E-08028 Barcelona, Spain

E-mail: gviscor@ub.edu

Received November 4, 2008; accepted in final form January 14, 2009. 
